\title{
On a generalization of Euler constant in connection to di-Gamma function
}

\section{LASZLO BALOG}

\section{ABSTRACT.}

In this paper we study the sequences $\left\{x_{n}\right\},\left\{y_{n}\right\}$ defined for each $n \geq 1$ by

$$
x_{n}=\frac{1}{a}+\frac{1}{a+1}+\cdots+\frac{1}{a+n-1}-\ln \left(\frac{a+n}{a}+b\right),
$$

and

$$
y_{n}=\frac{1}{a}+\frac{1}{a+1}+\cdots+\frac{1}{a+n-1}-\ln \left(\frac{a+n-1}{a}+b\right),
$$

where $a \in(0,+\infty)$ and $b \in\left[0, \frac{1}{2 a}\right]$, in connection to Gamma and di-Gamma function.

Our results generalize some previous ones in [Berinde, V. A new generalization of Euler's constant, Creat. Math.Inform. 18 (2009), No. 2, 123-128] and [Sântămărian, A., A generalization of Euler constant, Mediamira, Cluj-Napoca, 2008] and are inspired from the paper [Mortici, C., Improved convergence towards generalized Euler-Mascheroni constant, Appl. Math. Comput., 2009, doi: 10.1016/j.amc.2009.10.039].

NORTH UNIVERSITY OF BAIA MARE

DEPARTMENT OF MATHEMATICS AND COMPUTER SCIENCE

Victoriei 76, 430122 BAia MARE, ROMANiA

E-mail address: balog_58@yahoo.com

Received: 30.08.2011; In revised form: 30.11.2011; Accepted: 31.12.2011

2010 Mathematics Subject Classification. 11Y60, 40A05.

Key words and phrases. The Euler-Mascheroni constant, Gamma function, Digamma function. 